\title{
A Healthy School Environment as a Precondition for the Welfare of Students and Staff
}

\author{
Stela Georgiev ${ }^{\text {a }}$ \\ Mariela Kamburov \\ Manolya Un
}

\begin{abstract}
A healthy school environment is an important element of the Coordinated School Health model, which periodically focuses on the quality of a school's physical and esthetic surroundings as well as its psychosocial climate, safety, and culture. According to previous studies, the characteristics of a school environment are statistically related to the students' health and academic achievement. Therefore, the purpose of this paper is to examine various aspects of a school environment, their influences on the well-being of the school community, and the need for improvements. A comprehensive study on school health promotion was conducted with a representative sample of schools in the region of Pleven, Bulgaria. Data were collected by means of a self-administered questionnaire among students, parents, and staff as well as through interviews with school principals. In the region of Pleven, there are a total of 118 schools, which were built between 1912 and 1998. The majority of the buildings have been renovated, and the school surroundings are generally well-maintained. However, approximately $60 \%$ of the buildings have no easy access for disabled persons, and according to the school documents, any deviations from the standards of temperature, lighting, and ventilation in the classrooms have not been registered. In addition, approximately $40 \%$ of the respondents felt that improvements in human relationships and job satisfaction would create a healthier school community. Based on the findings, the influence of a healthy school environment on the welfare and academic performance of students and staff is confirmed and such an environment should be a precondition for the welfare of other school communities.
\end{abstract}

Keywords: Health promotion $\bullet$ Healthy school environment $\bullet$ Students 'health $\bullet$ School environments $\bullet$ Bulgaria

a Corresponding author

Assist. Prof. Stela Georgieva, Ph.D., Department of Public Health Sciences, Faculty of Public Health, Medical University - Pleven, Bulgaria

Research areas: Public health; School environments; Welfare and health

Email: georgieva_sl@yahoo.com

b Prof. Mariela Kamburova, MD, Ph.D., Department of Public Health Sciences, Faculty of Public Health, Medical University - Pleven, Bulgaria

Email: mariela_kamburova@yahoo.com

c Manolya Un, Faculty of Medicine, Medical University - Pleven, Bulgaria

Email: manolyaun@gmail.com 
Since health and education have a direct effect on individuals, society, and the economy, it is important to ensure that learning and health are interrelated. In this regard, schools are the perfect setting for such collaboration because they foster young people during the most important periods of their lives, and they can directly influence students' health-related behaviors and outlooks on life (Centers for Disease Control and Prevention (CDC), 2014; World Health Organization (WHO), 2003). School health promotion includes various activities that can contribute to the physical, mental, and social well-being of students and staff (CDC, 2004). In addition, a healthy school environment is an important element of the Coordinated School Health model (CSH), which incorporates a broad spectrum of issues concerning the quality of a school's physical and esthetic surroundings as well as its psychosocial climate, safety, and culture (Figure 1).

\section{Health \\ Education}

Family/

Community

Involvement

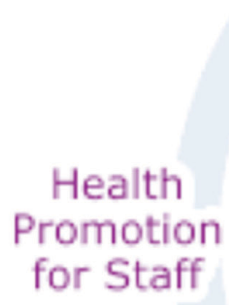

Healthy

School

Environment
Physical

Education

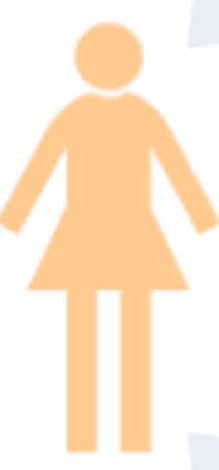

Nutrition

Services

\section{Health}

Services

\section{Counseling, Psychological, \& Social Services}

Figure 1: Coordinated School Health model (NC Healthy Schools, n.d.). 
All of the model's dimensions (physical, psychosocial, and organizational) have an impact on the health and well-being of the members of a school community (Allensworth, Lawson, Nicholson, \& Wyche, 1997; Kickbusch, Jones, \& O'Byrne, 1998). Thus, the health promoting school concept includes expanding the original component of a healthy and safe school environment into two distinct components: the effect of the physical environment and the effect of social and emotional climate (Figure 2).

\section{Healty and safe school environment}

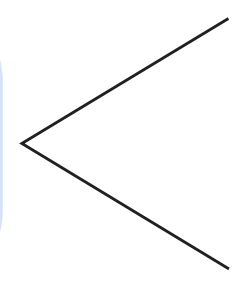

\section{Socialand emotional elimate}

Figure 2: Components of a healthy and safe school environment.

This division meets the need for a greater emphasis on both the psychosocial and physical environment as well as the promotion of safety, inclusiveness, better interpersonal relationships, etc. There have been different theories describing the complex causal pathways via which school effects on health may occur (Bonell et al., 2013). The school environment is a crucial factor for students' academic commitment, cognition, and behavior. In addition, the school buildings and physical surroundings as well as various safety and hygiene standards can have a positive impact on health, value, and overall school ethos (Fletcher, Bonell, \& Hargreaves, 2008; Lister-Sharp, Chapman, Stewart-Brown, \& Sowden, 1999). Furthermore, previous studies have shown that physical and social environments are statistically related to students' overall academic achievement including academic performance (class grades, standardized tests, and graduation rates), education behavior (attendance, dropout rates, and behavioral problems), and cognitive skills and attitudes (concentration, memory, and mood) (Bradley \& Green, 2013; CDC, 2010). 


\section{Objective}

The purpose of this paper is to examine various aspects of a school environment, their influences on the well-being of the school community, and the need for improvements in the region of Pleven, Bulgaria.

\section{Materials and Methods}

\section{Time and Location of the Study}

A comprehensive medico-social study on health promotion at schools was conducted from September 2012 to May 2013 using a representative sample of schools in the region of Pleven, Bulgaria.

\section{Data Collection}

Data were collected by means of a self-administered questionnaire among students, parents, and staff (1,280 total subjects) as well as through interviews with school principals. A specially designed tool, comprised of various assessment questions, focused on the following: $(a)$ physical characteristics of the school environment; $(b)$ health education process at the school; and $(c)$ students' mental and emotional well-being at the school. Factors that influence the physical environment (the school building and its surroundings), any biological or chemical agents, and physical conditions (temperature, noise, and lighting) were additionally observed through document review. Furthermore, in order to increase the validity of the results, available data regarding the aforementioned factors were provided by the regional health authorities of other regions of Bulgaria.

\section{Data Analysis}

Data analysis and interpretation were consistent with the health promoting school concept. Statistical data processing was carried out with Microsoft Office Excel 2010 and SPSS for Windows v.13.0. 


\section{Results}

\section{Physical Environment}

In the region of Pleven, there are total of 118 schools, which were built between 1912 and 1998. The majority of the buildings have been renovated and the school surroundings are well-maintained (Figure 3). However, approximately $60 \%$ of the buildings have no easy access for disabled persons and, according to various school documents, deviations from the standards of temperature, lighting, and ventilation in the classrooms have not been registered. Overall, the physical components of the school environments have been strictly controlled and the recommendations of the regional health authorities have been fulfilled.

\section{Psychosocial Environment}

In regard to the psychosocial, emotional, and organizational components, the subjects in this study broadly agreed that their respective school environments were mainly healthy. However, they stated that the following improvements (Figure 4) are necessary in order to create a healthier school community:

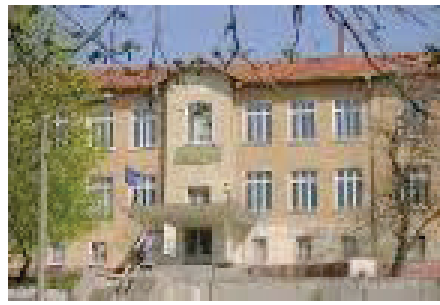

Figure 3: The oldest school building in the Pleven region, which was built in 1912 .

Better opportunities for sports and nutrition services

Improvements in human relationships

Decreasing stress levels in the work environment

Improvements in job satisfaction 


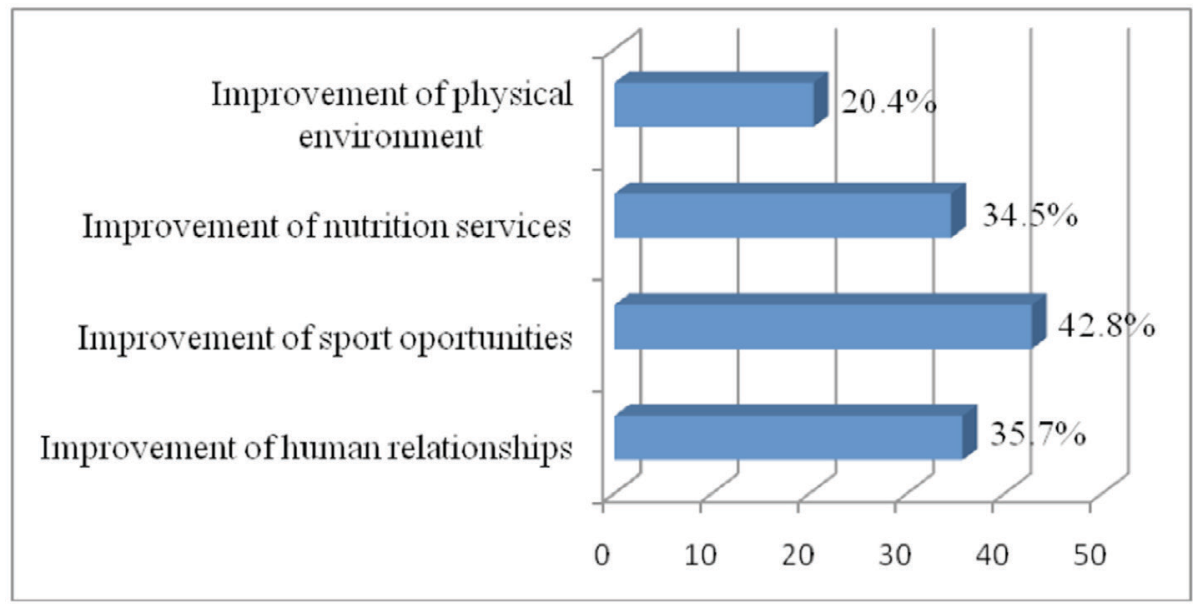

Figure 4: Necessary improvements in the school environment, according to the subjects in this study

\section{Sports Opportunities}

The observation of sports opportunities found that, in roughly $10 \%$ of the schools, there was no gymnasium. In more than half of the schools in which there was a gymnasium, the facility did not completely satisfy the needs of the curriculum. Such a deficiency was compensated by adapting certain rooms and areas of the school building, which provided a weak opportunity (although mainly seasonal) to practice various sports such as football, basketball, handball, and table tennis. The conditions of the sports facilities and the disinfestations of various sites and lawns were documented by the regional health authorities. In addition, a series of evaluations, coinciding with the time period of this study, did not find serious violations that endangered the health and safety of the children.

\section{Nutrition Services}

Some type of nutrition services have been found at two-thirds of the observed schools. Moreover, the assortment of food complied with the requirements for the nutrition of children in the particular age groups and it was controlled by the authorities. 


\section{Human Relationships}

Two-thirds of the investigated students stated that some type of aggression occurred daily in their school lives. More than half (51.6\%) defined it as "relational aggression" while $7.1 \%$ referred to it as "physical aggression." In addition, $41.3 \%$ stated that both physical and relational aggression occurred at their respective schools.

\section{Stress in the Occupational Environment}

Subjective feelings of stress among school staff was distributed in both the medium and high categories ( $47.2 \%$ each). The main sources of stress related to the work environment, according to the school staff, included noise, performing tasks under limited time conditions, conflicts with colleagues, students, and parents as well as poor organization of working time (Figure 5).

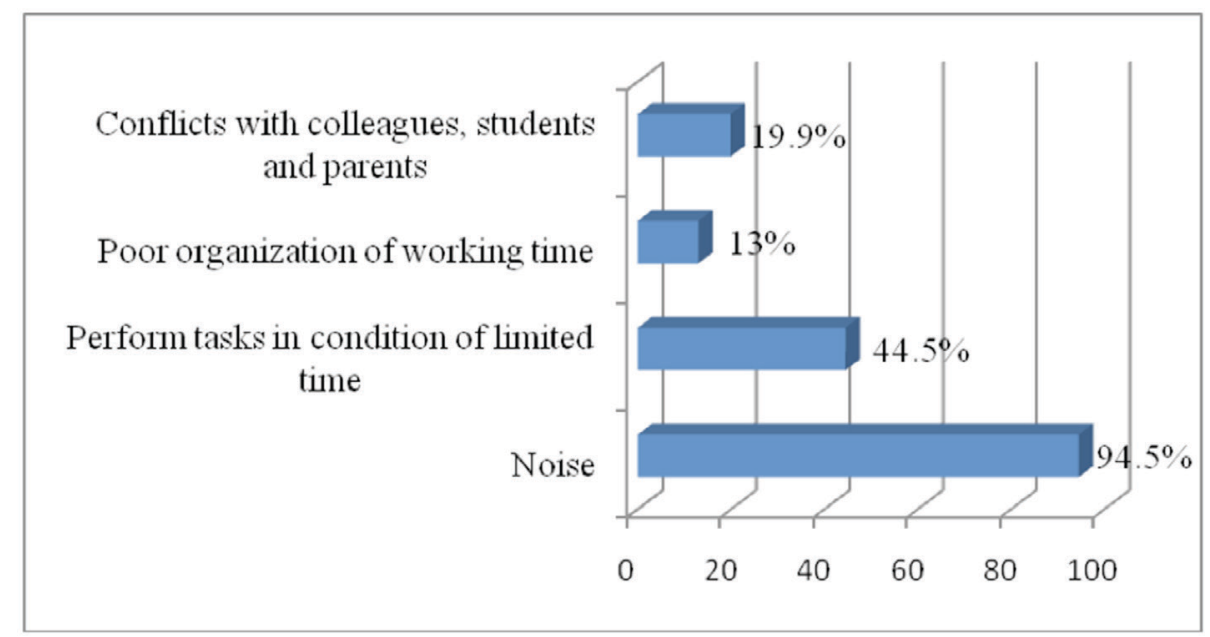

Figure 5: Main sources of stress related to the work environment at the schools, according to the school staff.

Students associated stress due to poor organization of the curriculum, information congestion, and conflicts with teachers and classmates (Figure 6). 


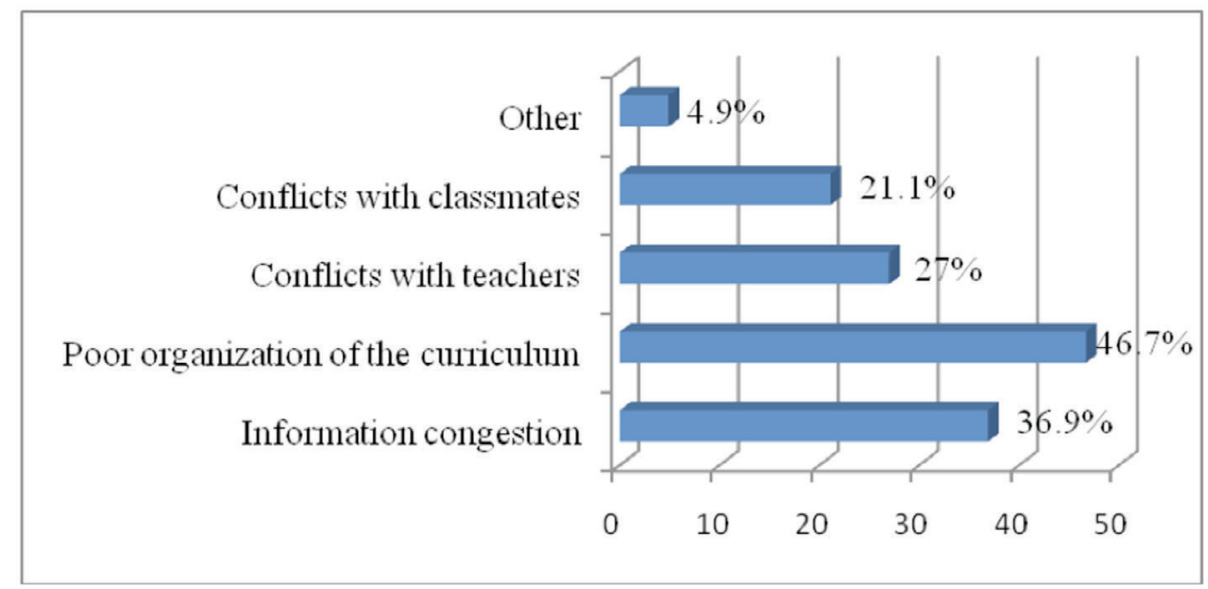

Figure 6: Main sources of stress related to the work environment at the schools, according to the students.

\section{Job Satisfaction}

Stress levels that affected the mental and social well-being of the students and school staff, are reflected in their job satisfaction and academic performance. Three-quarters of the respondents stated that they were satisfied with their work. Approximately every fifth person, however, felt dissatisfied and wanted to search for work elsewhere, if possible. The results also showed a statistically significant correlation between

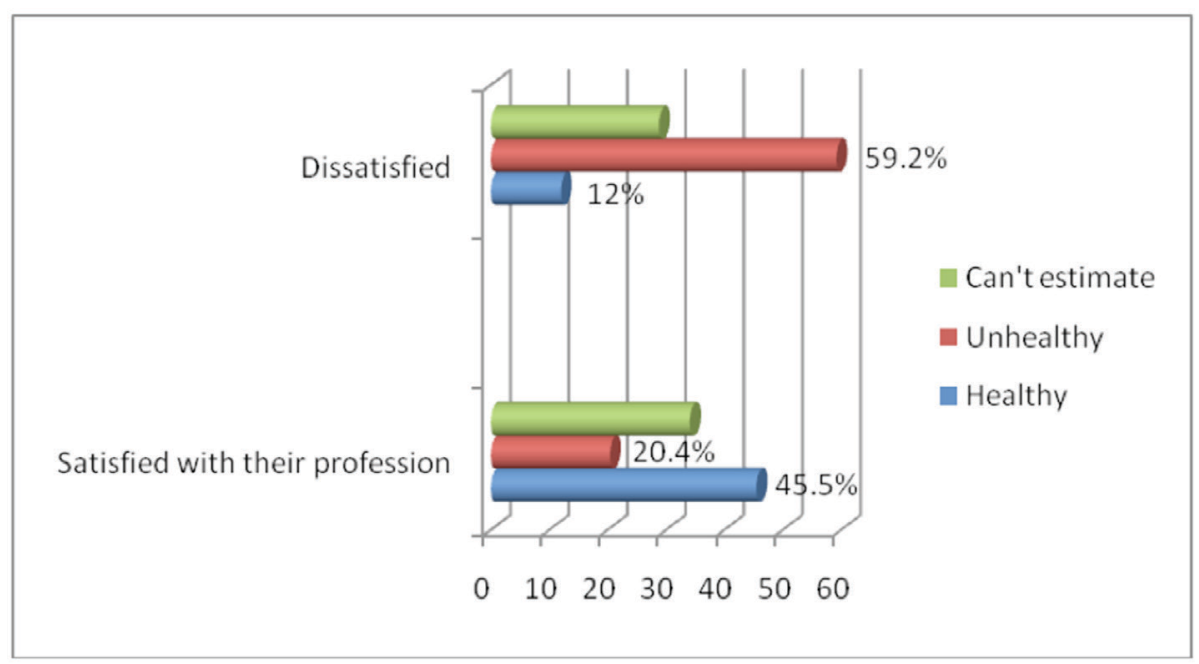

Figure 7: Correlation between job satisfaction and the overall perception regarding the beneficial influence of the environment. 
the sense of job satisfaction and the motivation to work $(p=.03)$. Moreover, jobsatisfied individuals reported lower levels of stress and improvements in their overall perception regarding the beneficial influence of the environment $(p=.0001)$.

\section{Discussion}

Factors that generally influence the physical environment include the school building and its surroundings, any biological or chemical agents that are detrimental to health, and physical conditions such as temperature, noise, and lighting (Wingspread Declaration, 2004). According to the present study's results, the physical components of the environment corresponded to the hygiene standards and positively impacted the health of the students and staff. One serious disadvantage was the lack of facilities with easy access for disabled persons. Based on the health promoting school concept, such a drawback makes it more difficult for those with physical disabilities to become involved in their respective school communities (WHO, 2003)

The psychological environment includes physical, emotional, and social conditions that can affect the well-being of students and staff. Thus, schools should enable learning by celebrating individual interests and recognizing the unique qualities of both the students and staff. It has been shown that the development of a positive social and emotional climate increases academic achievement, reduces stress, and improves overall positive attitudes (Frumkin, Geller, Rubin, \& Nodvin, 2006).

In the present study, after conducting interviews with the school principals, the activities aimed at creating a positive human environment and the prerequisites for mental and social well-being were discussed. The results show that all of the observed schools were attempting to create opportunities of creative expression for both the students and staff. Various activities to stimulate informal contacts and create friendships as well as a sense of belonging to the school were also being carried out. The findings also show that disadvantaged children (handicapped, minority groups) were well-adapted to the community.

Conversely, some cases of aggressive behavior were observed. Aggression can take various forms that may be expressed physically and intended to harm another.More frequently, relational aggression is expressed by offensive words, social exclusion, etc. (Hill et al., 1996). This phenomenon was reported by $66 \%$ of the respondents 
and it has been defined as a source of psychosocial stress in the work environment. However, psychological support for aggressive students and their victims have been provided by the school psychologists (permanently appointed at about one-third of the schools), teachers, and families.

Physical education provides age-appropriate activities for students to improve their health status, reduce stress, and increase social development (Bradley \& Green, 2013; CDC, 2010). Studies have demonstrated that when children's basic fitness needs are met, they attain higher achievement levels (CDC, 2010; Taras, 2005a, 2005b; Trudeau \& Shepard, 2008).

Finally, although nutrition is a separate element of the eight-component health promoting school concept, it can also be seen as an environmental condition that positively enhances social and emotional climates as well as increases learning outcomes (Murphy et al., 1996; Rampersaud, Pereira, Girard, Adams, \& Metzl, 2005; Taras, 2005a, 2005b). Therefore, improvements in sports possibilities and nutrition services should be designated as one of the necessary improvements in the environments of the observed schools.

\section{Conclusions}

Bulgarian schools are in accordance with the health promoting schools concept.

The influence of school environments on health and academic performance was realized and communities should make a concerted effort to maintain healthy school environments.

Physical components of the environment are under strict control of the regional health authorities. Deviations of the hygiene standards were not found.

Opportunities for school-based physical education and nutrition should be improved.

Improvements in interpersonal relationships can help decrease relational aggression.

Better organization of the curriculum can lead to a decrease in the stress levels of the students and staff. 
Job satisfaction enhances the motivation to work and it improves the overall perception regarding the beneficial influence of the environment (with statistically significant association).

\section{Limitations of the Study}

First, this comprehensive study, including the members of various school communities, only focused on schools in the region of Pleven, Bulgaria. Thus, regarding the situation in other regions of the country, we employed information provided by the regional health authorities in those areas. Second, the physical component of the environment was not measured by our research team. Instead, we simply reviewed various school documents.

\section{Acknowledgement}

We wish to express our gratitude to the regional health authorities and to the various school principals for their assistance in the research process.

\section{References}

Allensworth, D., Lawson, E., Nicholson, L., \&Wyche, J. (1997). Schools and health: Our nation's investment. Retrieved from http://www.nap.edu/catalog/5153.html

Bonell, C. P., Fletcher, A., Jamal, F., Wells, H., Harden, A., Murphy, S., \& Thomas, J. (2013). Theories of how the school environment impacts on student health: Systematic review and synthesis. Health \& Place, 24, 242-249.

Bradley, B., \& Green, A. C. (2013). Do health and education agencies in the United States share responsibility for academic achievement and health? A review of 25 years of evidence about the relationship of adolescents' academic achievement and health behaviors. Journal of Adolescent Health, 52(5), 523-532.

Center for Disease Control and Prevention. (2004). Coordinated school health model. Retrieved from http://www.cdc.gov/nccdphp/aag/pdf/aag_dash2004.pdf

Centers for Disease Control and Prevention. (2010). The association between school based physical activity, including physical education, and academic performance. Atlanta, GA: U.S. Department of Health and Human Services. 
Centers for Disease Control and Prevention. (2014). Whole school, whole community, whole child. A collaborative approach to learning and health. Retrieved from http:/www.ascd.org/ ASCD/pdf/siteASCD/publications/wholechild/wscc-a-collaborative-approach.pdf

Fletcher, A., Bonell, C., \& Hargreaves, J. (2008). School effects on young people's drug use: A systematic review of intervention and observational studies. Journal of Adolescent Health, 42, 209-220.

Frumkin, H., Geller, R., Rubin, L., \& Nodvin, J. (Eds.). (2006). Safe and healthy school environment. New York, NY: Oxford University Press.

Hill, M. W., \& Robert, H. H., Sugai, G., Bullis, M., Sprague, J. R., Bricker, D., \& Kaufman, M. J. (1996). Integrated approaches to preventing antisocial behavior patterns among school-age children and youth. Journal of Emotional and Behavioral Disorders, 4(4), 194-209.

Kickbursh, I.,Jones, T.J., O’Byme, D. (1998). Promoting the world health organisation's concept of health. UNESCO International Science, Technology \& Environmental Education Newsletter, XXIII, 2-4. Retrieved from http://www.unesco.org/education/ educprog/ste/pdf_files/connect/connect98-2.pdf

Lister-Sharp, D. J., Chapman, S., Stewart-Brown, S., \& Sowden, A. (1999). Health promoting schools and health promotion in schools: Two systematic reviews. Health Technology Assessment, 3(22), 1-207.

Murphy, J. M., Pagano, M. E., Nachmani, J., Sperling, P., Kane, S., Kleinman, R. E. (1998). The relationship of school breakfast to psychosocial and academic functioning. Archives of Pediatrics and Adolescent Medicine, 152(9), 899-907.

NC Healthy Schools. (n.d.). Eight component model. Retrieved from http://www. nchealthyschools.org/components/

Rampersaud, G. C., Pereira, M. A., Girard, B. L., Adams, J., \& Metzl, J. D. (2005). Breakfast habits, nutritional status, body weight, and academic performance in children and adolescents. Journal of the American Dietetic Association, 105(5), 743-760.

Taras, H. (2005a). Nutrition and student performance at school. Journal of School Health; 75(6), 199-213.

Taras, H. (2005b). Physical activity and student performance. Journal of School Health, 75(6), 214-218.

Trudeau, F., \& Shepard, R. J. (2008). Physical education, school physical activity, sports and academic performance. International Journal of Behavioral Nutrition and Physical Activity, 5(10). Retrieved from http://www.ijbnpa.org/content/5/1/10 
Wingspread Declaration: A National Strategy for Improving School Connectedness. (2004). Journal of School Health, 74(7), 233-234.

World Health Organization. (2003). Creating an environment for emotional and social well-being. An important responsibility of a health-promoting and child friendly school (Information Series on School Health Document, 10). Retrieved from http://www. who.int/school_youth_health/media/en/sch_childfriendly_03.pdf 